\title{
Utidelone inhibits growth of colorectal cancer cells through ROS/JNK signaling pathway
}

\author{
Fuli Li', Tinglei Huang ${ }^{1}$, Yao Tang ${ }^{1}$, Qingli Li', Jianzheng Wang ${ }^{2}$, Xiaojiao Cheng ${ }^{1}$, Wenhui Zhang ${ }^{3}$, Baiwen Zhang ${ }^{1}$, \\ Cong Zhou ${ }^{1}$ and Shuiping Tu ${ }^{1}$
}

\begin{abstract}
Utidelone (UTD1), a novel microtubule stabilizing agent, is an epothilone B analogue which was produced by genetic engineering. UTD1 has exhibited broad antitumor activity in multiple solid tumors. However, its activity and mechanism in colorectal cancer (CRC) remain to be studied. In this study, UTD1 dramatically inhibited CRC cell proliferation (with $0.38 \mu \mathrm{g} / \mathrm{ml}, 0.77 \mu \mathrm{g} / \mathrm{ml} \mathrm{IC50}$ in RKO and HCT116, respectively) in vitro. Immunofluorescence staining showed that UTD1 induced the formation of microtubule bundling and asters in RKO cells. Flow cytometry analysis demonstrated that UTD1 induced cell cycle to arrest in G2/M phase, subsequent apoptosis. Significantly, UTD1 exhibited stronger effect on inducing apoptosis than paclitaxel and 5-FU, especially in HCT15 cells which is ABCB1 high-expression. UTD1 exposure cleaved caspase-3 and poly ADP-ribose polymerase (PARP), decreased mitochondrial

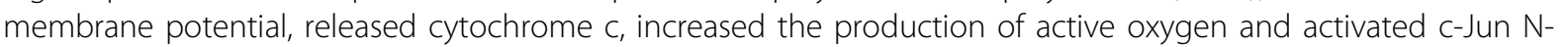
terminal kinase (JNK), suggesting ROS/JNK pathway was involved in this process. Moreover, UTD1 inhibited tumor growth and was more effective and safer compared with paclitaxel and 5-FU in RKO xenograft in nude mice. Taken together, our findings first indicate that UDT1 inhibits tumor growth in CRC xenograft model and may be a promising agent for CRC treatment.
\end{abstract}

\section{Introduction}

Colorectal cancer (CRC) is one of the most common tumors in the world. More than 2 million people are diagnosed with CRC every year ${ }^{1,2}$. Treatments for CRC include chemotherapies, endoscopic and surgical excision, targeted therapies, local ablative therapies, and immunotherapies ${ }^{3-6}$. Although there are multiple treatments, CRC still is the leading cause of cancer-related deaths ${ }^{7,8}$. Among various treatments, chemotherapies occupy an important role in advanced colorectal cancer, but

\footnotetext{
Correspondence: Shuiping Tu (tushuiping@yahoo.com)

${ }^{1}$ State Key Laboratory of Oncogenes and related Genes, Department of Oncology, Renji Hospital, School of Medicine, Shanghai Jiao Tong University, Shanghai 200127, China

2Department of Oncology, the Affiliated Cancer Hospital of Zhengzhou University, Henan Cancer Hospital, NO.127, Dongming Road, Zhengzhou 450008, China

Full list of author information is available at the end of the article

These authors contributed equally: Fuli Li, Tinglei Huang
}

Edited by A. Stephanou chemotherapy drugs available in colorectal cancer are limited. Consequently, there remains a significant medical need to find new drugs for CRC.

Antimitotic drugs, also called microtubule targeted drugs, are classified as microtubule-stabilizing or microtubule-destabilizing agents according to their influence on microtubule dynamics. Microtubulestabilizing agents include taxanes and epothilones. Conversely, vincristine, colchicine, and maytansine belong to microtubule-destabilizing agents ${ }^{9-12}$. Taxanes are approved for various solid tumors such as breast cancer, ovarian cancer, and non-small cell lung cancer ${ }^{13,14}$. Epothilones, which involve epothilone A, B, C, D, E, and F, have anticancer activities similar to paclitaxel, and competed with paclitaxel for binding sites on microtubules ${ }^{15}$. There are now a variety of epothilones and its analogues having entered clinical trials. Ixabepilone (BMS-247550) is the only epothilone analogue approved by the Food and Drug Administration ${ }^{16,17}$. Utidelone (UTD1), a novel

\section{(c) The Author(s) 2021}

(c) (i) Open Access This article is licensed under a Creative Commons Attribution 4.0 International License, which permits use, sharing, adaptation, distribution and reproduction cc) in any medium or format, as long as you give appropriate credit to the original author(s) and the source, provide a link to the Creative Commons license, and indicate if changes were made. The images or other third party material in this article are included in the article's Creative Commons license, unless indicated otherwise in a credit line to the material. If material is not included in the article's Creative Commons license and your intended use is not permitted by statutory regulation or exceeds the permitted use, you will need to obtain permission directly from the copyright holder. To view a copy of this license, visit http://creativecommons.org/licenses/by/4.0/. 
microtubule stabilizing agent, is an epothilone B analogue. In breast cancer, UTD1 showed significant antitumor activity and has entered phase III clinical trials ${ }^{18-21}$.

It demonstrated that CRC failed to response to paclitaxel in clinical trials because of serious side effects or multidrug resistance ${ }^{22,23}$. Colorectal cancer constitutively overexpressed P-glycoprotein (P-gp), which is encoded by the multidrug resistance gene (MDR1, ABCB1). P-gp can efflux many structurally and functionally diverse chemotherapeutics, leading to resistance. A lot of chemotherapeutics, such as paclitaxel, docetaxel, and doxorubicin are $\mathrm{P}$-gp substrates ${ }^{24}$. However, unlike paclitaxel, epothilones were less influenced by P-gp; this may be one of the reasons why epothilones were effective in paclitaxel-sensitive and -resistant tumors ${ }^{25,26}$. Preclinical studies indicated that epothilones and its analogues had anticancer activity in CRC cells ${ }^{27-29}$. And a phase I clinical study showed that Ixabepilone coadministration with sunitinib had encouraging clinical activity in metastatic CRC patients ${ }^{30}$. In addition, epothilones are with high water solubility and more tolerable toxicity, and are proved to have fewer side effects compared with paclitaxel. These findings suggest that UTD1 might have antitumor activity for CRC. However, antitumor activity of UTD1 in CRC model has not been investigated.

In this study, we determined the effects of UTD1 on CRC in vitro and in vivo. We found that UTD1 significantly inhibited proliferation of CRC cells in a dose- and time-dependent manner. Flow cytometry showed UTD1induced cell cycle to arrest in G2/M phase and followed by apoptosis, which involved ROS/JNK pathway. Furthermore, UTD1 suppressed growth of tumors and was more effective and safer.

\section{Results \\ UTD1 reduced viability and inhibited proliferation of human CRC cells in vitro}

We first evaluated direct effect of UTD1 on proliferation and survival of CRC cells. UTD1 significantly induced growth inhibition in a dose- and time-dependent manner in RKO and HCT116 cells. After $72 \mathrm{~h}$ of incubation, IC50 of RKO and HCT116 cells were $0.38 \mu \mathrm{g} / \mathrm{ml}$ and $0.77 \mu \mathrm{g} /$ $\mathrm{ml}$, respectively (Fig. 1A). We chose $1 \mu \mathrm{g} / \mathrm{ml}$ UTD1 for further experiments according to IC50 values. To investigate time efficacy, cells were exposed to $1 \mu \mathrm{g} / \mathrm{ml}$ UTD1 for different time-points, inhibition rate of cells increased as incubation was prolonged. Cells exposed to UTD1 exhibited morphological changes, including membrane blebbing, cell shrinkage, nuclear condensation, and fragmentation (Fig. 1B).

To confirm inhibitory effect of UTD1 on cell proliferation, colony formation assay was performed. Consistent with above observations, colony number was reduced in UTD1-treated group in a time-dependent manner (Fig. 1C). These results suggested that UTD1 could suppress proliferation and growth of RKO and HCT116 cells.

\section{UTD1 changed morphology of tubulin and induced cell cycle to arrest in G2/M phase}

Because UTD1 is one of the microtubule-stabilizing agents, we investigated the effect of UTD1 on cell microtubule. Immunofluorescence staining showed that UTD1 caused polymerization of microtubule (Fig. 2A), as the formation of polymerized microtubule bundles after $12 \mathrm{~h}$. There were mitotic asters visible after $24 \mathrm{~h}$. To elucidate UTD1's mode of action, its effect on cell cycle progression was examined. Flow cytometry analysis showed RKO cells arrested in G2/M phase (Fig. 2B), and same results were observed in HCT116 as well as RKO cells which were treated with paclitaxel (Fig. S1A, B). Importantly, more than $60 \%$ RKO cells arrested at G2/M phase after being treated with UTD1 after $12 \mathrm{~h}$, while it was less than $40 \%$ in the paclitaxel group. To further determine cell cycle arrest in G2/M phase, Western blotting was performed. Consistent with flow cytometry result, proteins mainly appearing in $\mathrm{G} 2 / \mathrm{M}$ phase such as cyclinB1, cyclinA2, CDC2, and P21 were decreased (Fig. $2 \mathrm{C})$. These results suggested that UTD1 could change microtubule morphology and block cell cycle at G2/M phase.

UTD1 induced apoptosis by activating caspase- 3 and PARP after G2/M arrest and was more effective than paclitaxel

To determine the consequence of UTD1-induced cellcycle arrest, we evaluated annexin V-FITC/PI staining of treated cells. $48 \mathrm{~h}$ later, percentage of apoptosis was approximately $85 \%$ in RKO cells (Fig. 3A, C left). Cells treated with UTD1 for $48 \mathrm{~h}$ showed drastic increase in apoptosis compared with control group. Pretreatment with a pan-caspase inhibitor, Z-VAD-FMK could reduce apoptosis (Fig. 3B, C right), indicating this apoptotic process required caspase activation. In HCT116 cells, duration of cell arrest was relatively long, and occurrence of apoptosis was delayed (data not shown). Therefore, we chose RKO cells for the following experiments. To further prove caspase involved in UTD1-mediated apoptosis, we examined activation of caspase- 3 and PARP by immunofluorescence staining and Western blotting. Activation of caspase- 3 was confirmed by immunofluorescence, in which only cleaved caspase-3 was stained (Fig. 3D). Immunoblots of whole-cell lysates showed typical $89-\mathrm{kDa}$ products of PARP cleavage as early as $24 \mathrm{~h}$, accompanied by decrease of un-cleaved form of PARP (Fig. 3E top). Pretreatment with Z-VAD-FMK could reduce PARP cleavage and restore the level of un-cleaved PARP (Fig. 3E bottom). TEM also demonstrated that RKO cells underwent apoptosis after being exposed to UTD1. Cells 

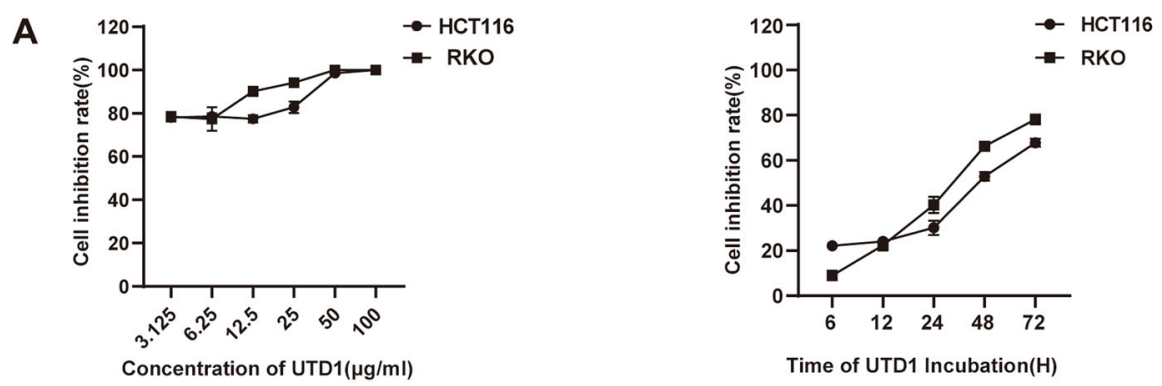

B
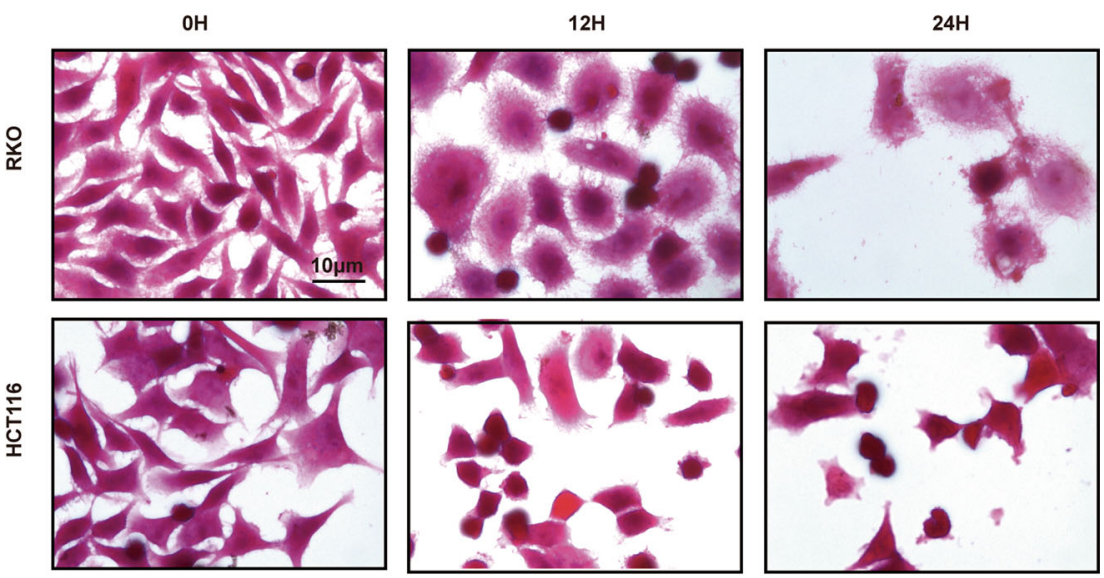

C
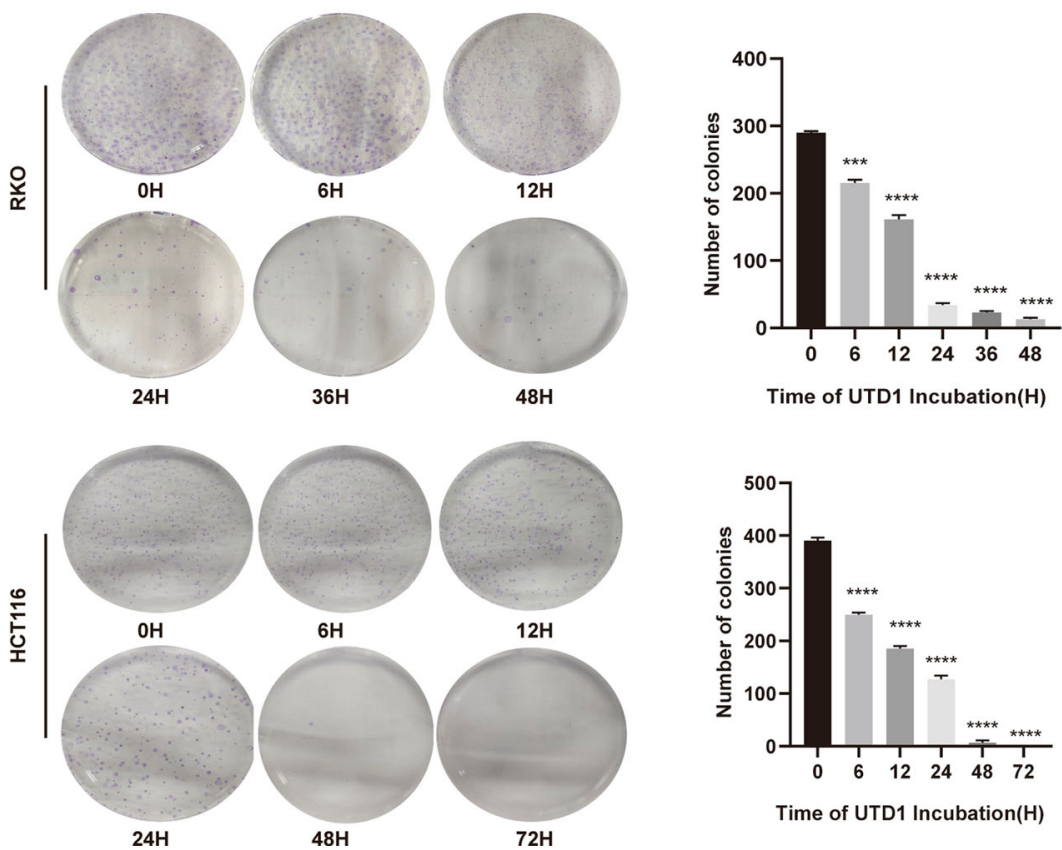

Fig. 1 UTD1 inhibited cell viability and proliferation in a dose- and time-dependent manner in CRC cells. A Cell viability was measured by CCK-8 after RKO and HCT116 cells were treated with different concentrations of UTD1 for $72 \mathrm{~h}$ or $1 \mu \mathrm{g} / \mathrm{ml}$ UTD1 for different time-points. B Morphology of cells treated with UTD1 for 0,12 , and $24 \mathrm{~h}$. Scale bar $=10 \mu \mathrm{m}$. C Colony formation showed UTD1 reduced colony formation of RKO and HCT116 cells. All experiments were performed in triplicate. Results were presented as mean \pm SD, ${ }^{* * *} p<0.001,{ }^{* * * *} p<0.0005$ vs. control group. 


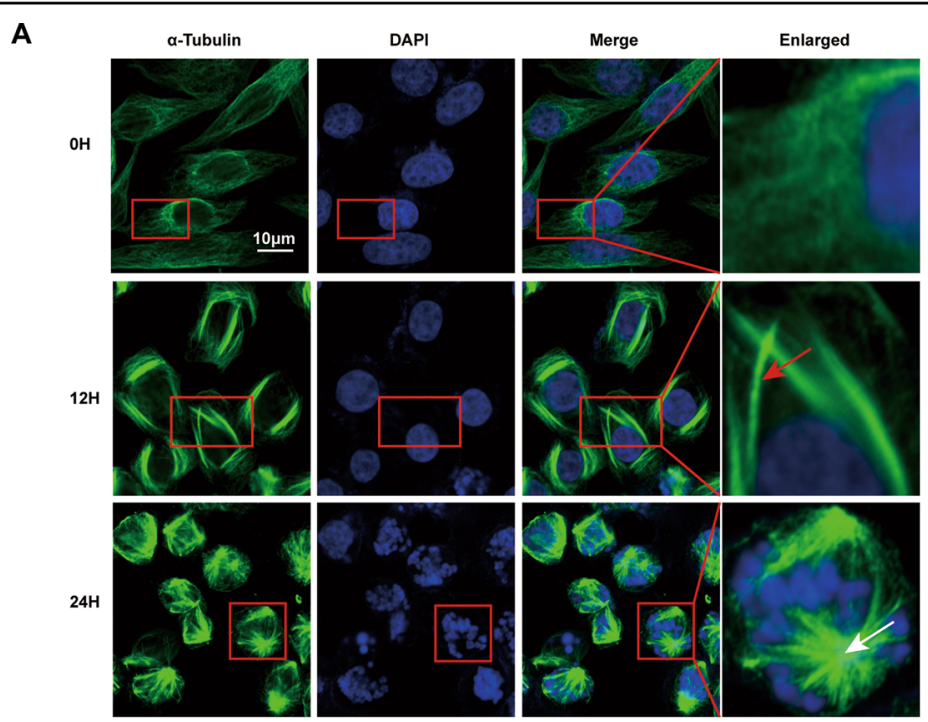

B
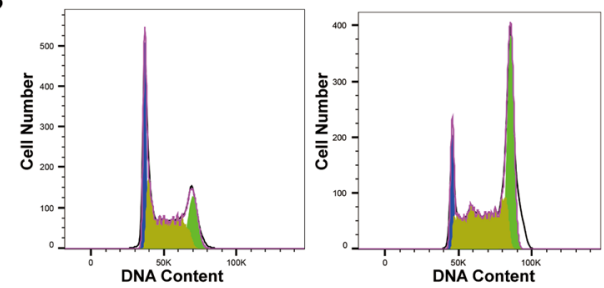

$\mathrm{OH}$

$6 \mathrm{H}$
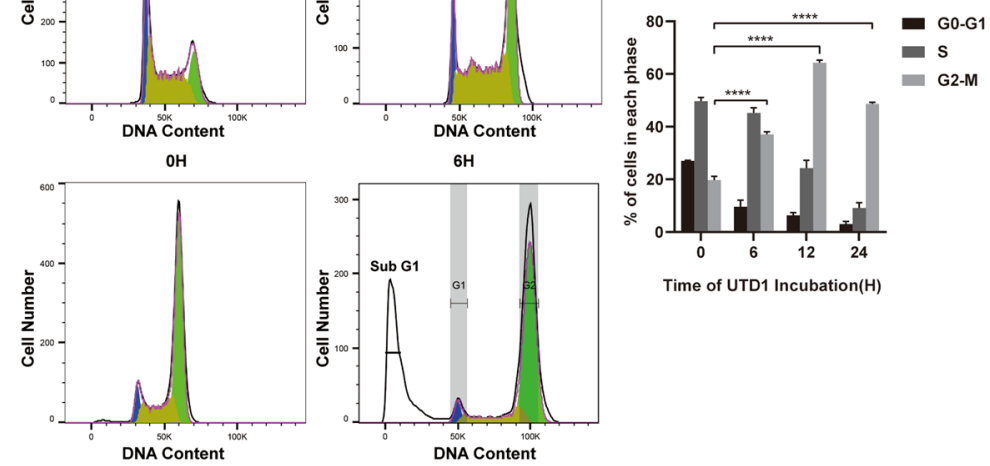

$12 \mathrm{H}$

$24 \mathrm{H}$
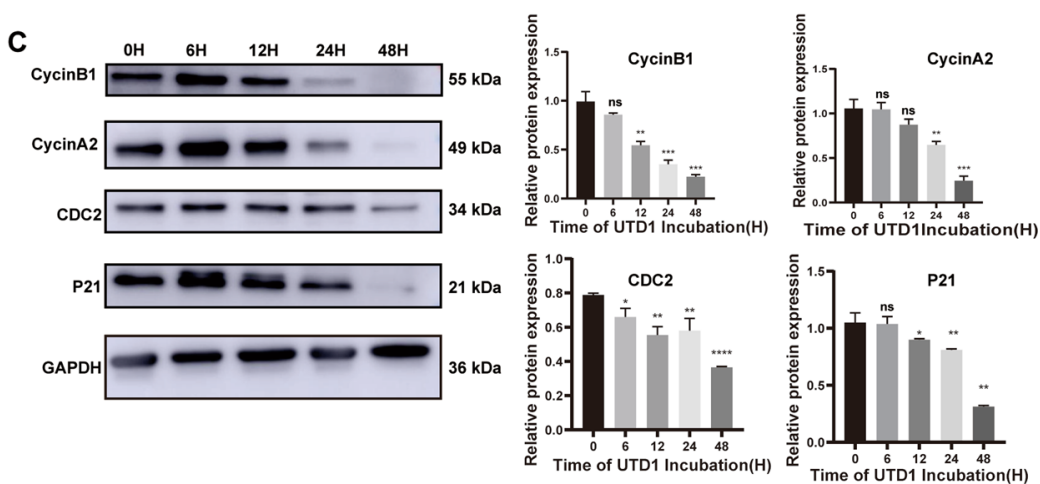

Fig. 2 UTD1 changed morphology of tubulin and induced cell cycle to arrest in G2/M phase. A Immunofluorescence staining was used to detect morphological change of tubulin after RKO cells were incubated with UTD1. Red and white arrowheads in panels indicate formation of microtubule bundles and asters, respectively. Scale bar $=10 \mu \mathrm{m}$. B After treatment, RKO cells were fixed, stained, and analyzed. Flow cytometry showed that UTD1 arrested cell cycle in G2/M phase. C Proteins involved in G2/M phase were analyzed by Western blotting. All experiments were performed in triplicate. Results were presented as mean \pm SD. ns: no statistically significant difference, ${ }^{*} p<0.05,{ }^{* *} p<0.01,{ }^{* * *} p<0.001,{ }^{* * * *} p<0.0005$ vs. control group. 
A

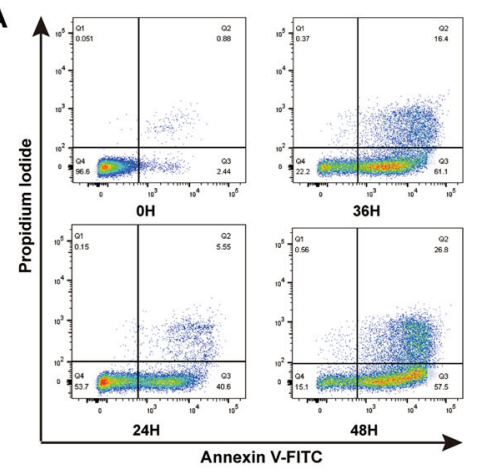

C

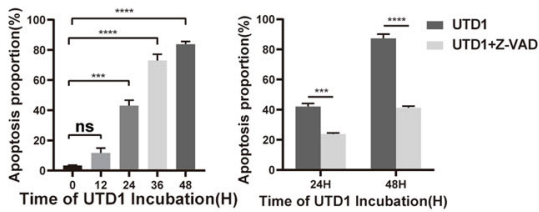

D

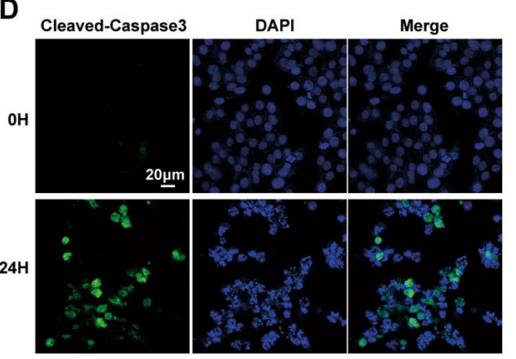

E
B

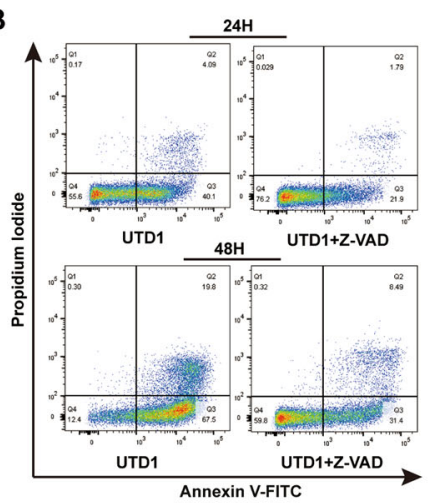

F

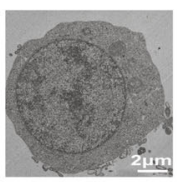

OH

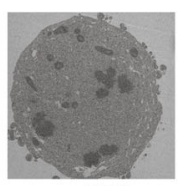

$12 \mathrm{H}$

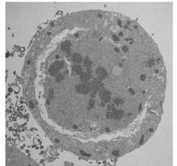

$36 \mathrm{H}$

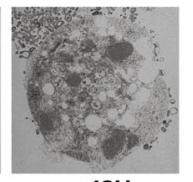

$48 \mathrm{H}$

$\begin{array}{lllll} & & & & \\ & \mathrm{OH} & 12 \mathrm{H} \quad 24 \mathrm{H} & 36 \mathrm{H} & 48 \mathrm{H}\end{array}$

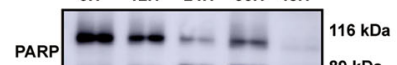

$89 \mathrm{kDa}$
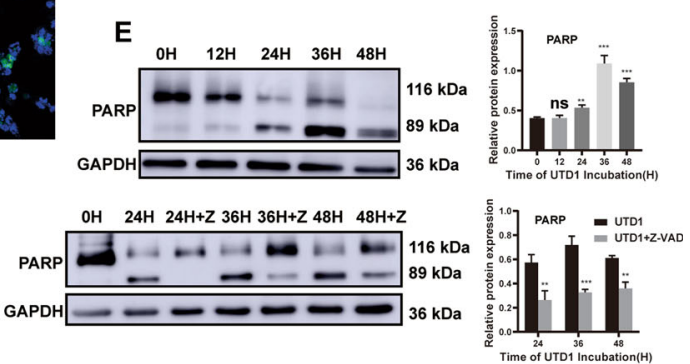

Time of UTD1 Incubation(H)

G

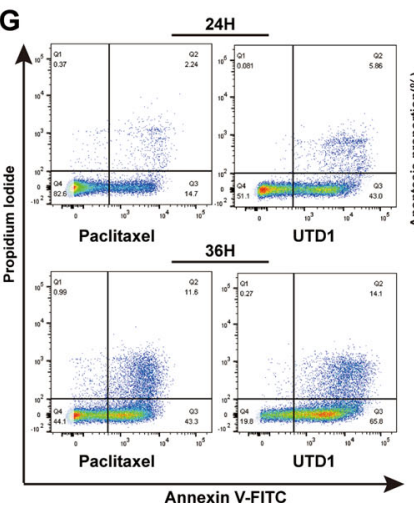

H
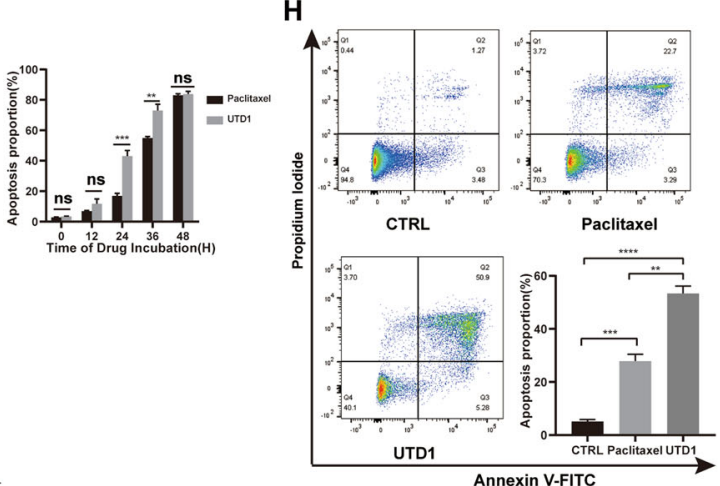

Fig. 3 UTD1 induced apoptosis in CRC cells and was more effective than paclitaxel. A Flow cytometry using Annexin V-FITC/PI double staining showed UTD1 triggered apoptosis in RKO cells. B Cells were preincubated with or without Z-VAD-FMK (50 $\mu \mathrm{m})$ for $2 \mathrm{~h}$, and then treated with $1 \mu \mathrm{g} / \mathrm{ml}$ UTD1. Apoptosis was detected by flow cytometry. C Statistical analysis of A and B. D Cleaved caspase-3 was detected after RKO cells were cultured with UTD1 using immunofluorescence staining. Scale bar $=20 \mu \mathrm{m}$. E RKO cells were incubated with UTD1 in the presence or absence of $50 \mu \mathrm{m}$ ZVAD-FMK. PARP was analyzed by Western blotting. F After exposure to UTD1, TEM was used to evaluate apoptosis. Scale bar $=2 \mu \mathrm{m}$. G After $1 \mu \mathrm{g} / \mathrm{ml}$ paclitaxel or UTD1 treated, flow cytometry was used to detect apoptosis of RKO cells. $\mathbf{H}$ After exposure to $50 \mu \mathrm{g} / \mathrm{ml}$ UTD1 or paclitaxel $24 \mathrm{~h}$, flow cytometry result showed apoptosis in HCT15 cells. All experiments were performed in triplicate. Results were presented as mean \pm SD. ns: no statistically significant difference, ${ }^{* *} p<0.01,{ }^{* * *} p<0.001,{ }^{* * *} p<0.0005$ vs. control group. 
A

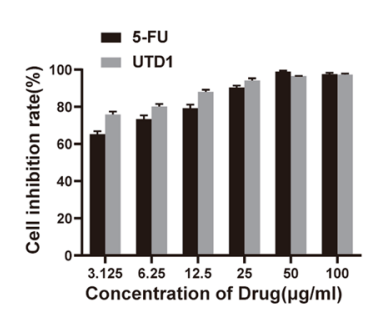

C

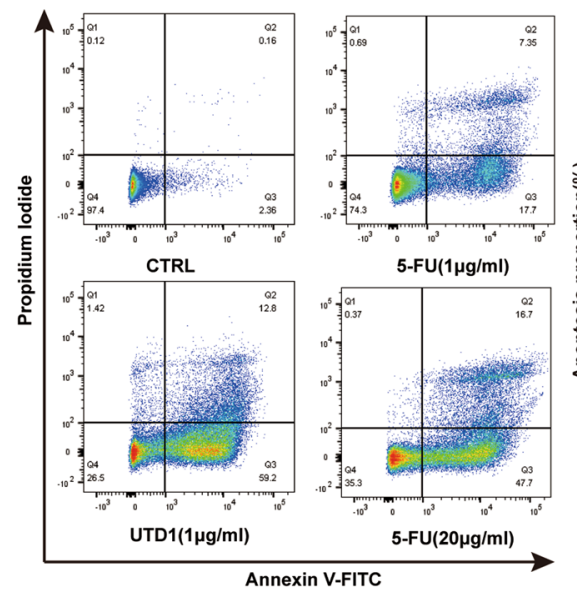

D

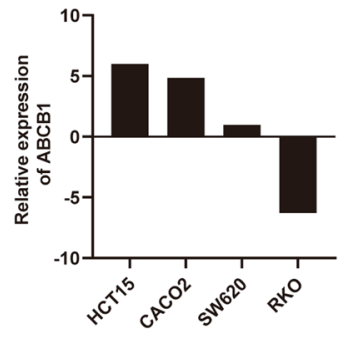

E
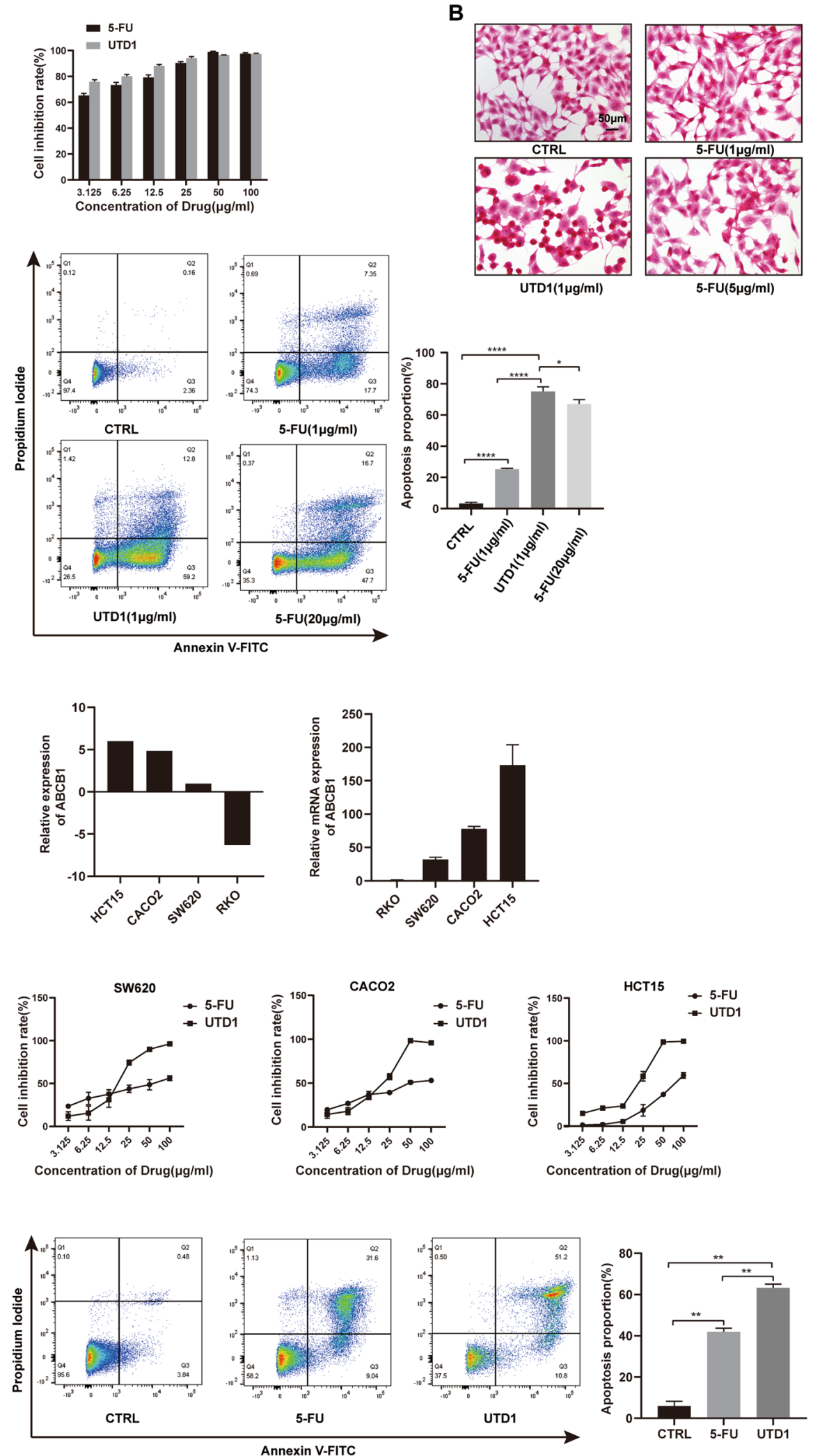

Annexin V-FITC

Fig. 4 (See legend on next page.) 
(see figure on previous page)

Fig. 4 UTD1 was more effective than 5-FU in vitro. A RKO cells were cultured with different concentrations of UTD1 and 5-FU for $72 \mathrm{~h}$. Cell viability was measured by CCK-8. B Morphology of RKO cells treated with $1 \mu \mathrm{g} / \mathrm{ml} \mathrm{UTD1}$ and $1 \mu \mathrm{g} / \mathrm{ml}, 5 \mu \mathrm{g} / \mathrm{ml} 5$-FU for $12 \mathrm{~h}$. Scale bar $=50 \mu \mathrm{m}$. C Annexin VFITC/PI staining showed UTD1 and 5-FU induced apoptosis in RKO cells. D CCLE database and qRT-PCR showed expression of ABCB1 in RKO, SW620, CACO2, and HCT15 cells. E SW620, CACO2, and HCT15 cells were treated with different concentrations of UTD1 and 5-FU, and cell viability was measured by CCK-8. F After being treated with $50 \mathrm{\mu g} / \mathrm{ml}$ UTD1 or 5-FU for $36 \mathrm{~h}$, flow cytometry was performed to test apoptosis of HCT15 cells. All experiments were performed in triplicate. Results were presented as mean $\pm \mathrm{SD},{ }^{*} p<0.05,{ }^{* *} p<0.01,{ }^{* * *} p<0.0005$ vs. control group.

showed typical morphological changes of apoptosis (Fig. 3F). After $12 \mathrm{~h}$, cytoplasm density increased, nucleus concentrated, and nuclear membrane broke. $48 \mathrm{~h}$ later, vesicle formed, and eventually cells dissolved. To compare the effect of UTD1 with paclitaxel, $1 \mu \mathrm{g} / \mathrm{ml}$ paclitaxel was used in RKO cells. Within $36 \mathrm{~h}$, UTD1 caused a higher proportion of cell death compared with paclitaxel (Fig. 3G). Importantly, UTD1 also induced more apoptosis in HCT15 cells (Fig. 3H). All results together suggested that UTD1 blocked CRC cell growth and survival via induction of apoptosis and was more effective than paclitaxel.

\section{UTD1 was more effective than 5-FU in vitro}

In clinical practice, 5-FU was the first-line chemotherapy for colorectal cancer. Therefore, antitumor activities of both UTD1 and 5-FU were compared. CCK-8 showed UTD1 and 5-FU could significantly inhibit growth in a dose-dependent manner in RKO cells (Fig. 4A). RKO cells exposed to UTD1 and 5-FU exhibited morphological changes (Fig. 4B). And morphology changed more drastically in UTD1-treated condition. Flow cytometry result also showed about $72 \%$ RKO cells underwent apoptosis after being exposed to $1 \mu \mathrm{g} / \mathrm{ml}$ UTD1 $36 \mathrm{~h}$, while only $25 \%$ in $1 \mu \mathrm{g} / \mathrm{ml} \mathrm{5-FU.} \mathrm{Furthermore,} 1 \mu \mathrm{g} / \mathrm{ml}$ UTD1 was even more effective than $20 \mu \mathrm{g} / \mathrm{ml} 5-\mathrm{FU}$ (Fig. 4C). ABCB1 is one of the mechanisms that induce tumor resistance, and it is usual high-expression in colorectal cancer. To study antitumor activities of UTD1 and 5-FU in cells with different levels of ABCB1, the CCLE database was used and results were verified by qRT-PCR using RKO cells as standard (Fig. 4D). CCK-8 suggested after UTD1 treatment, IC50 of SW620, CACO2, and HCT15 cells were $16.29,17.25$, and $18.88 \mu \mathrm{g} / \mathrm{ml}$, respectively, which were 51.45, 59.61, and $74.31 \mu \mathrm{g} / \mathrm{ml}$ after 5-FU exposure (Fig. $4 \mathrm{E})$. Flow cytometry result further indicated that there were more HCT15 cells undergoing apoptosis after being treated with UTD1 (Fig. 4F). All results suggested that UTD1 was more effective than 5-FU.

\section{UTD1 activated ROS/JNK pathway and induced apoptosis through mitochondrial-dependent pathway}

To detect pathway causing apoptosis, mitochondrial membrane potential was measured by TMRM/Mito Tracker Green. Mitochondrial membrane potential decreased in a time-dependent manner (Fig. 5A), and it was manifested by decrease of TREM and increase of Mito Tracker Green. It suggested UTD1 induced cell apoptosis through mitochondrial pathway. After administration of UTD1 or paclitaxel, TEM further showed that mitochondrial cristae dissolved and disappeared (Fig. 5B). To investigate whether ROS was enhanced because of UDT1 treatment, DCFH-DA was used. Cells treated with UTD1 exhibited dramatic enhancement in DCFH-DA fluorescent signal, and it could be scavenged by the antioxidant and ROS scavenger, Trolox (Fig. 5C). In agreement with DCFH-DA flow cytometry, annexin VFITC/PI staining demonstrated that apoptosis induced by UTD1 could be strongly inhibited by Trolox, especially early apoptosis (Fig. 5D). To gain further insight into the molecular mechanism of antitumor activity of UTD1, we investigated the effect of UDT1 on JNK pathway. Apoptosis of RKO cells could be decreased by JNK inhibitor, SP600125 (Fig. 5E, F left). The result of Western blotting further suggested that JNK was involved in apoptosis (Fig. 5G, F right). In addition, pretreatment with Trolox significantly reversed the phosphorylation of JNK (Fig. 5H), but production of ROS was not affected by SP600125 (data not shown). It suggested JNK activation was post ROS production. These results indicated UTD1 activated ROS/JNK pathway, consequently induced cell apoptosis through mitochondrial-dependent pathway.

\section{UTD1 affected mitochondrial dynamics}

Mitochondrial dynamics involves mitochondrial fusion and fission. To detect the effect of UTD1 on mitochondrial dynamics, immunofluorescence staining was used. After exposure to UTD1, mitochondrial fission protein, Drp1 almost coincided with tubulin (Fig. 6A). A similar phenomenon was found in mitochondrial fusion protein, Mitofusin-2 (Fig. 6B). These data suggested that UTD1 might affect mitochondrial dynamics, and eventually result in cell death.

\section{UTD1 inhibited tumor growth in RKO cell xenograft model and was more effective than paclitaxel and 5-FU}

To test the antitumor activity of UTD1 in vivo, RKO cell xenograft model was established. Compared with the control group, intraperitoneal administration of UTD1 significantly decreased the volume and weight of tumor in a dose-dependent manner (Figs. 7A, B, S2A). 


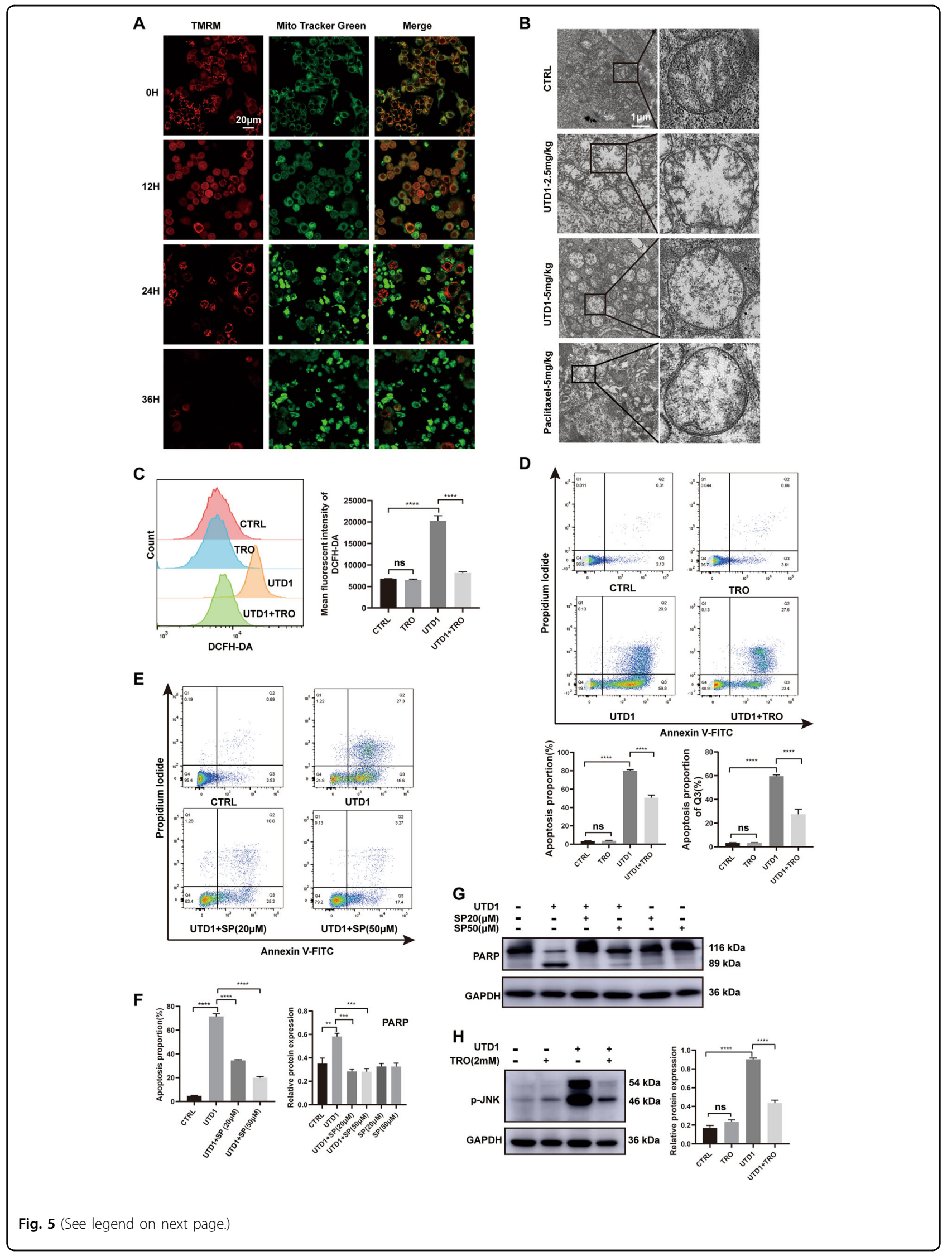


(see figure on previous page)

Fig. 5 UTD1 activated ROS/JNK signaling pathway and induced mitochondrial-dependent apoptosis. A Confocal microscopy showed mitochondrial membrane potential decreased after RKO cells were treated with UTD1. Scale bar $=20 \mu \mathrm{m}$. B TEM demonstrated morphology changes of mitochondria in tumor tissues which were treated with UTD1 or paclitaxel. Scale bar $=1 \mu \mathrm{m}$. C Flow cytometry showed ROS increased after incubation with UTD1, and it could be inhibited by Trolox. D Annexin V-FITC/PI staining showed pretreatment with Trolox $2 \mathrm{~h}$ could decrease apoptosis. E JNK inhibitor, SP600125, incubated with RKO cells $2 \mathrm{~h}$ before UTD1 added. Flow cytometry showed apoptosis was inhibited. F Statistical analysis of $\mathbf{E}$ and $\mathbf{G}$. G Western blotting showed SP600125 could inhibit apoptosis. H Antioxidant Trolox inhibited p-JNK induced by UTD1. All experiments were performed in triplicate. Results were presented as mean \pm SD. ns: no statistically significant difference, ${ }^{* *} p<0.01,{ }^{* * *} p<0.001$, ${ }^{* * * *} p<0.0005$ vs. control group.

Tumor suppression rates were 62.73 and $93.63 \%$ in $2.5 \mathrm{mg} / \mathrm{kg}$ and $5 \mathrm{mg} / \mathrm{kg}$ UTD1, respectively (Fig. 7C). Compared with $5 \mathrm{mg} / \mathrm{kg}$ paclitaxel, $5 \mathrm{mg} / \mathrm{kg}$ UTD1 could significantly inhibit tumor growth. And $2.5 \mathrm{mg} / \mathrm{kg}$ UTD1 was as effective as $25 \mathrm{mg} / \mathrm{kg}$ 5-FU (Figs. 7E, F, G, S2C). There was no statistical significance between $2.5 \mathrm{mg} / \mathrm{kg}$ UTD 1 and $25 \mathrm{mg} / \mathrm{kg} 5$-FU in tumor suppression rate (Fig. $7 \mathrm{H}$ ), probably suggesting that UTD1 was more effective than 5-FU. TUNEL-positive cells increased after UTD1 treatment (Fig. 7D). IHC showed that as UTD1 increased, expression of Ki-67 decreased, whereas p-JNK and Cytochrome C increased. UTD1 group increased more than paclitaxel group (Fig. S2B). These results suggested UTD1 could inhibit tumor growth in RKO cell xenograft model and was more effective than paclitaxel and 5-FU.

\section{UTD1 was safer than paclitaxel and 5-FU in vivo}

We further determined the safety of UTD1 in animal model. During 20 days' administration of drugs, little weight loss was observed in UTD1 group compared with paclitaxel and 5-FU groups (Fig. 8A, B). Furthermore, no significant changes were observed in the colors and textures of vital organs, including heart, liver, spleen, lung, and kidney (Fig. 8C). Survival rate of $5 \mathrm{mg} / \mathrm{kg}$ paclitaxel was $20 \%, 25 \mathrm{mg} / \mathrm{kg} 5$-FU was $80 \%, 5 \mathrm{mg} / \mathrm{kg}$ UTD1 was $80 \%$, and $2.5 \mathrm{mg} / \mathrm{kg}$ UTD1 was $100 \%$ (Fig. 8D, E). Whole blood cell analysis indicated blood cell count decreased less than paclitaxel after UTD1 treatment (Fig. 8F). The indexes of liver, kidney, and heart function showed $5 \mathrm{mg} /$ kg UTD1 group was closer to control group, although they were all within normal range (Fig. 8G, H, I). These results confirmed that UTD $12.5 \mathrm{mg} / \mathrm{kg}$ and even $5 \mathrm{mg} / \mathrm{kg}$ did not cause obvious systemic toxicity in vivo. Under the same conditions, UTD1 was safer than paclitaxel. And with same antitumor effect, UTD1 was needed less than 5-FU; thus it had fewer side effects.

\section{Discussion}

Paclitaxel is widely used in treating varieties of solid tumors. But it failed in CRC clinical trials because of side effects or multidrug resistance ${ }^{22,23}$.

In this study, we investigated antitumor activity of UTD1 compared with paclitaxel and 5-FU in human CRC cells and explored underlying molecular mechanisms. Our results showed that UTD1 inhibited cell proliferation and colony formation, altered microtubule dynamics, blocked cells at G2/M phase followed by apoptosis. Importantly, UTD1 was more effective than paclitaxel and 5-FU, especially in ABCB1 high-expression cells, such as HCT15 cells.

Microtubule-stabilizing agents are known to cause microtubule polymerization ${ }^{31,32}$. As one of microtubulestabilizing agents, effect of UTD1 on microtubule was consistent with previous studies ${ }^{33,34}$. After UTD1 exposure, microtubule bundles and asters formed. Antimicrotubule agents arrested cells in G2/M phase ${ }^{35-37}$. In our research, flow cytometry revealed that UTD1 could induce cell cycle $\mathrm{G} 2 / \mathrm{M}$ block in a time-dependent manner.

Li et al. ${ }^{38-40}$ have reported after being blocked by antimitotic drugs for a long time that cells underwent apoptosis mainly through mitochondrial pathway. Our findings clearly demonstrated that mitochondrial membrane potential was decreased, and caspase- 3 and PARP were cleaved after UTD1 incubation. UTD1 treatment increased the level of ROS, which could activate JNK, increase the phosphorylation of JNK, eventually resulting in cell death. These suggested that ROS/JNK pathway might be involved. Mitochondrial dynamics have been reported associated with cell death ${ }^{41}$, after exposure to UTD1, both mitochondrial fission and fusion protein, Drp1 and Mitofusin2 changed, indicating that UTD1 might affect mitochondrial dynamics, which also could trigger cell death.

Given the activity of UTD1 against CRC cells in vitro, it was important to evaluate it in preclinical CRC xenograft model. In vivo, UTD1 significantly inhibited growth of CRC. Compared with the same dose of paclitaxel, tumor volume was significantly reduced in UTD1 group. And $2.5 \mathrm{mg} / \mathrm{kg}$ UTD1 was as effective as $25 \mathrm{mg} / \mathrm{kg} 5-\mathrm{FU}$. Compared with four mice dead in paclitaxel group, UTD1 caused only one mouse death. And there was less body weight loss in UTD1 group compared with paclitaxel and 5-FU groups. The safety assessment of UTD1 group was closer to that of control group. These data suggested that UTD1 displayed robust antitumor activity in CRC xenograft model with controllable toxicity. 


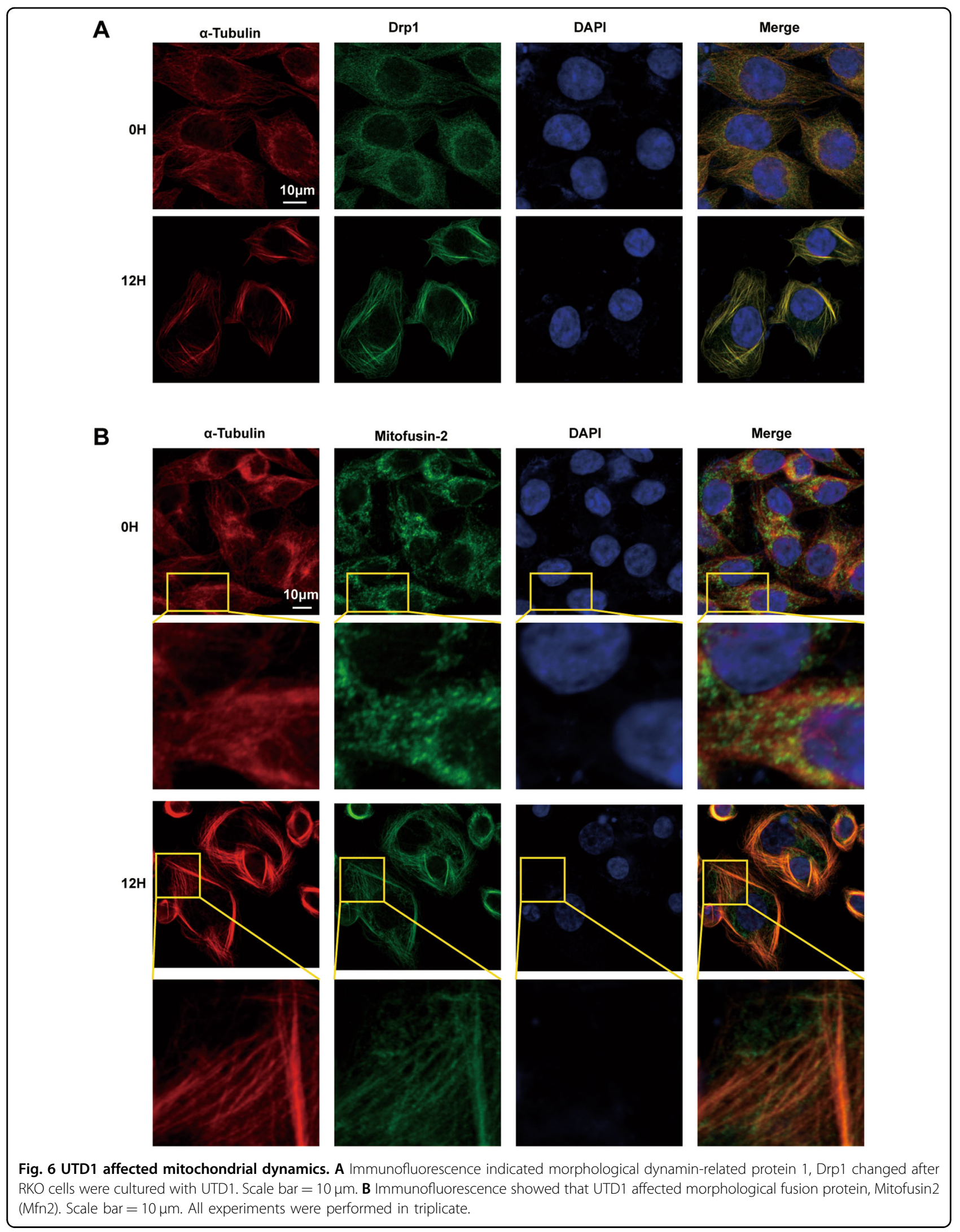



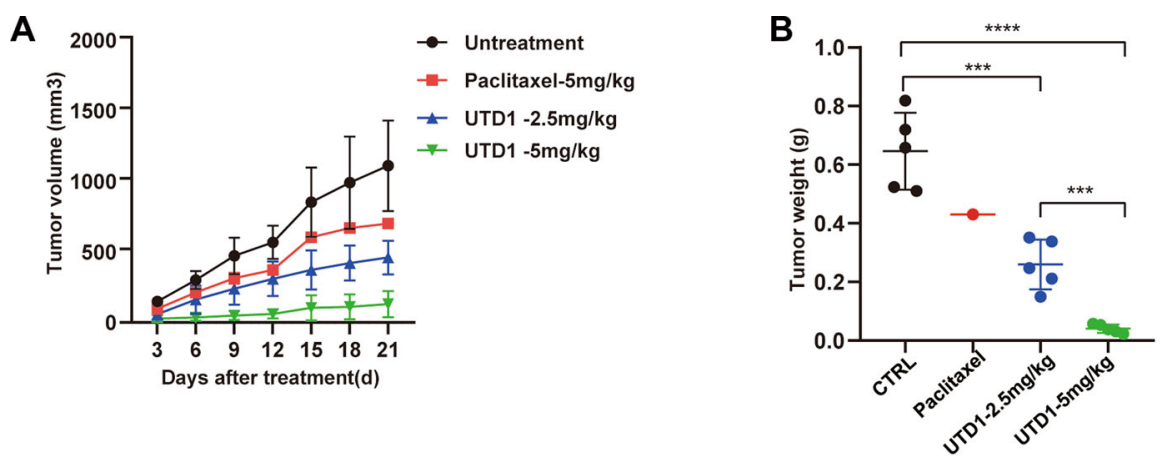

C

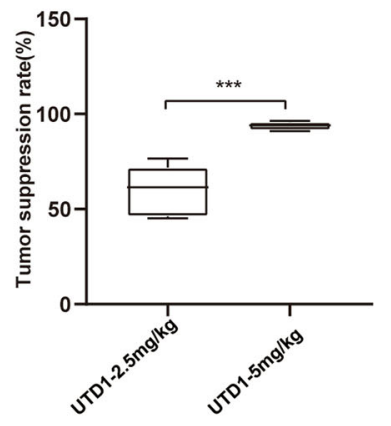

E

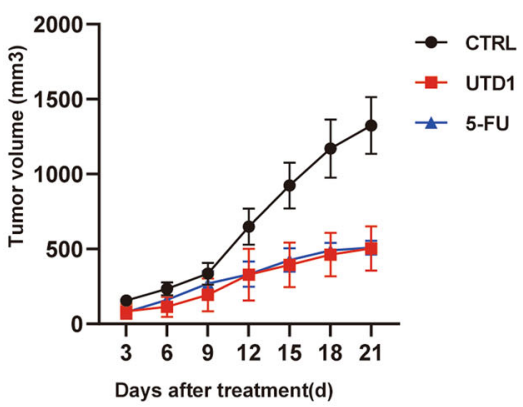

G

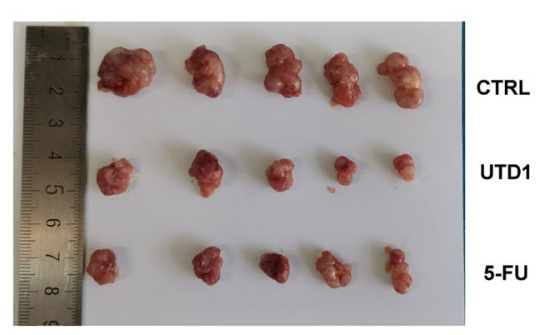

D

CTRL
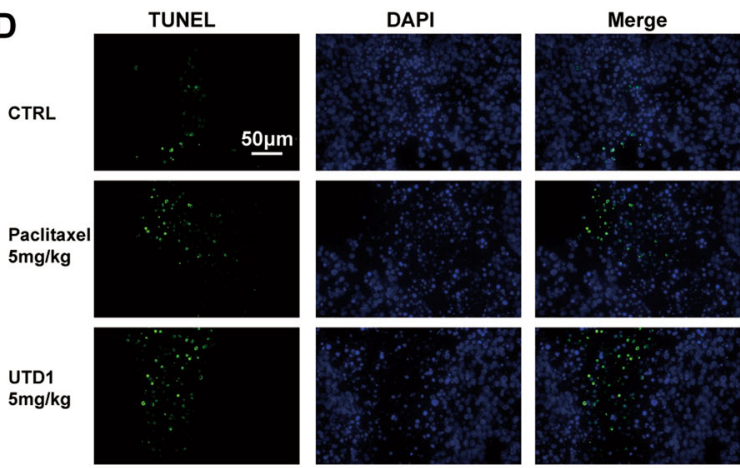

$\mathbf{F}$

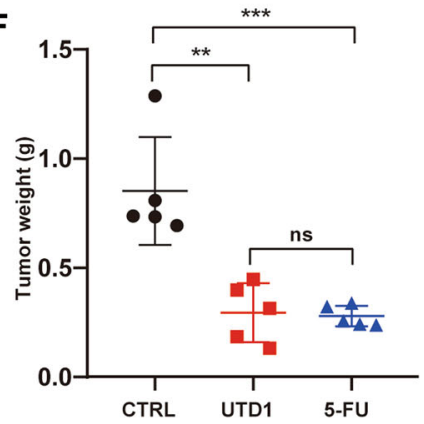

H

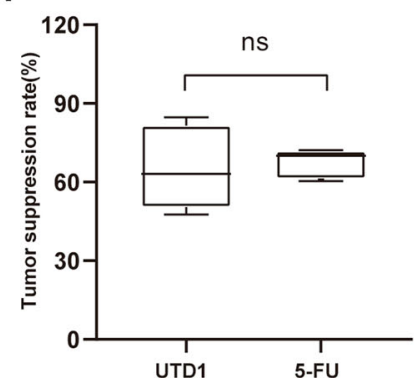

Fig. 7 UTD1 suppressed growth of RKO cell xenograft tumor and was more effective than paclitaxel and 5-FU. A Changes in tumor volume during UTD1 and paclitaxel administration. B Tumor weights at the end of the experiment. C Tumor suppression rates of 2.5 and $5 \mathrm{mg} / \mathrm{kg}$ UTD1. D TUNEL staining of tumor tissue. Scale bar $=50 \mu \mathrm{m}$. $\mathbf{E}$ Changes in tumor volume during UTD1 and 5-FU administration. $\mathbf{F}$ Tumor weights at the end of the experiment. G Image of xenograft tumor. H Tumor suppression rates of $2.5 \mathrm{mg} / \mathrm{kg}$ UTD1 and $25 \mathrm{mg} / \mathrm{kg} 5$-FU. Results were presented as mean \pm $\mathrm{SD}$, ns: no statistically significant difference, ${ }^{* *} p<0.01,{ }^{* * *} p<0.001,{ }^{* * *} p<0.0005$ vs. control group. 
A

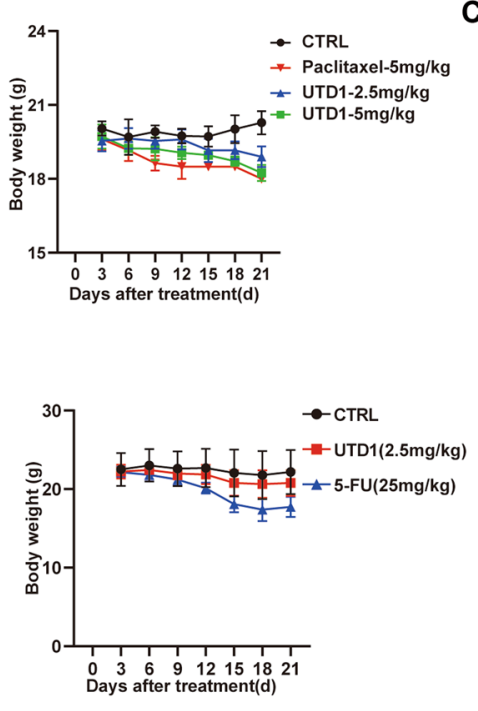

D

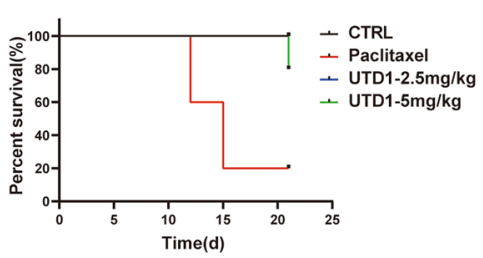

F

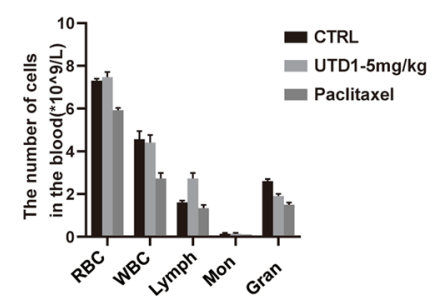

G

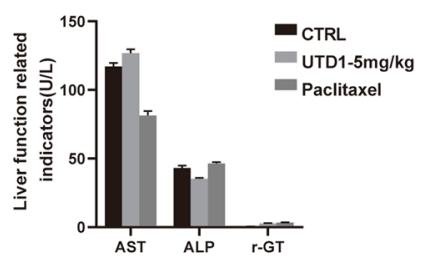

H

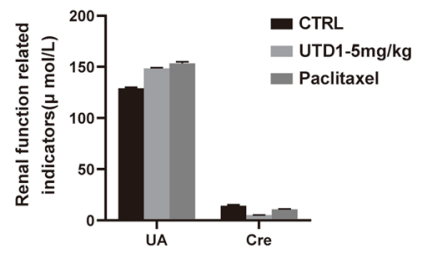

C CTR

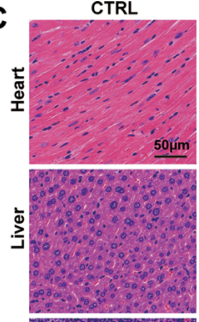

UTD1-2.5mg/kg
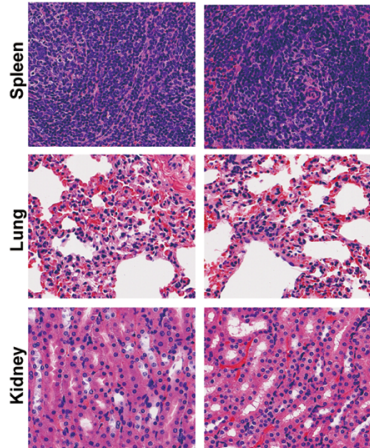

E
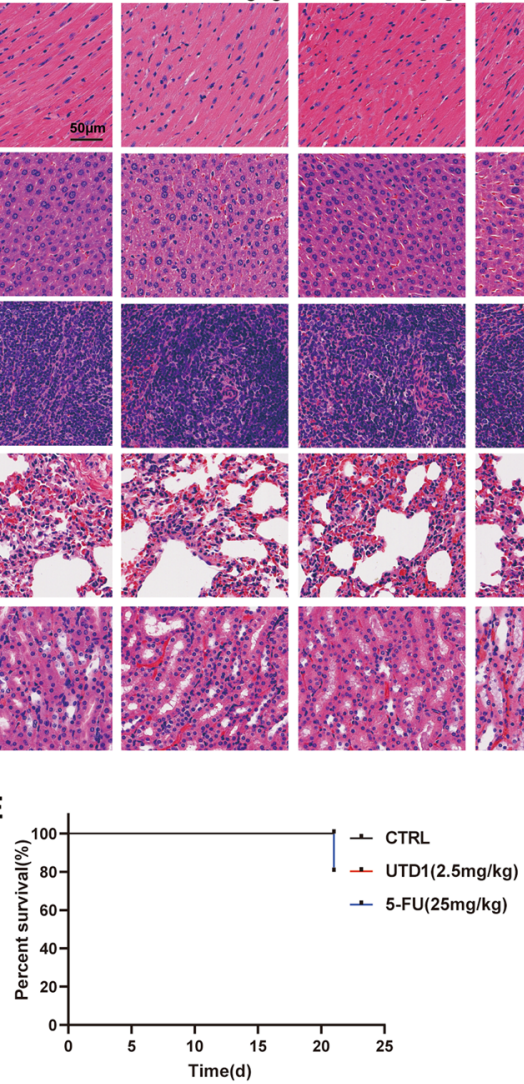

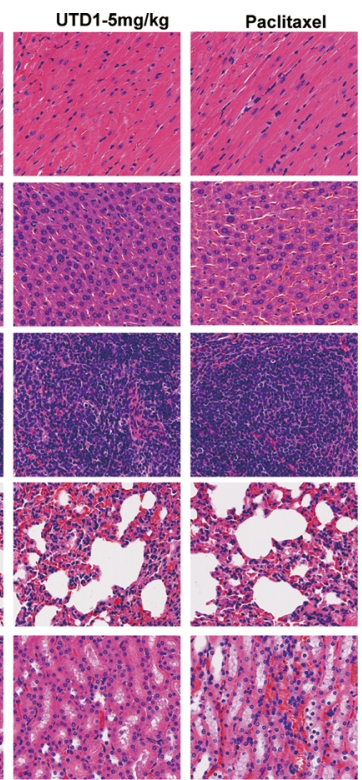

.


In summary, UTD1 is efficacious in suppressing the growth of CRC cells. Furthermore, it has considerable antitumor efficacy with tolerable side effects in vivo. We anticipate that UTD1 may prove to be a promising agent in CRC therapy.

\section{Materials and methods}

\section{Cell lines and culture}

Human CRC cell lines RKO, HCT116, CACO2, SW620, and HCT15 were purchased from Cell Culture Center of Institute of Basic Medical Sciences, Chinese Academy of Medical Sciences. Cells were cultured in RPMI-1640 medium with 10\% Fetal Bovine Serum (FBS) and 1\% penicillin and streptomycin (Gibco), and incubated at $37^{\circ} \mathrm{C}$ under an atmosphere of $95 \%$ air and $5 \% \mathrm{CO}_{2}$.

\section{Materials}

In vitro, UTD1, paclitaxel, and 5-Fluorouracil (5-FU) (stock solution $10 \mathrm{mg} / \mathrm{ml}$ ) were diluted in complete medium according to required concentration before use. Complete medium was used as control. In vivo, drugs were diluted in $0.9 \%$ sodium chloride aqueous solution before administration. And $0.9 \%$ sodium chloride aqueous solution was used as control. RPMI-1640 medium, FBS, and crystal violet were purchased from SIGMA. PI/RNase Staining Buffer and FITC Annexin V Apoptosis Detection Kit were purchased from BD Biosciences. Paclitaxel, 5-FU, Z-VAD-FMK, SP600125, and Trolox were purchased from Med Chem Express (Shanghai, China). Antibodies against cyclinB1, CDC2, P21, PARP, Cleaved caspase-3, cytochrome C, phospho-JNK, Ki-67, Drp1, Mitofusin-2, and secondary antibody were purchased from Cell Signaling Technology (Beverly, MA, USA). CyclinA2, glyceraldehyde-3-phosphate dehydrogenase (GAPDH), $\alpha$ Tubulin, and secondary antibody were purchased from Abcam (UK).

\section{Cell proliferation assay}

Cell proliferation activity was detected using Cell Counting Kit-8 (CCK-8) (Dojindo, Japan). RKO, HCT116, SW620, CACO2, and HCT15 cells were seeded in a 96well plate. Different concentrations of UTD1 and 5-FU were added and incubated for 72 hour (h) or $1 \mu \mathrm{g} / \mathrm{ml}$ UTD1 was added and incubated for different time-points. According to the protocol provided, CCK- 8 working solution was added and incubated for $3 \mathrm{~h}$ at $37^{\circ} \mathrm{C}$; absorbance was measured at $450 \mathrm{~nm}$ with a microplate reader (PerKinElmer). IC50 was calculated using GraphPad Prism8.

\section{Cell morphology}

To investigate the effect of UTD1 and 5-FU on cell morphology, cells were seeded in a 6-well plate with cover slips at a density of $2 \times 10^{5} / \mathrm{ml}$. UTD1 and 5 -FU were added and incubated. Cells were fixed with 95\% ethanol for $15 \mathrm{~min}$, stained with hematoxylin and eosin (HE). Cell morphology changes were observed with microscopy (Leica DM6 B).

\section{Colony formation assay}

Crystal violet was used to detect colony formation of cells. After being incubated with UTD1, 1000 cells/well were seeded in a 6-well plate. Medium was changed in 2-3 days and incubated for 14 days. The colonies were fixed with $100 \%$ methanol and stained with $0.5 \%$ crystal violet. The numbers of colony were counted by microscopy (OLYMPUS CKX53).

\section{Immunofluorescence staining assay}

Microtubule morphology changes, apoptosis, and mitochondrial changes were observed by immunofluorescence staining assay. Cells $\left(3 \times 10^{3}\right.$ cells/well $)$ were dispensed in chamber on poly-D-lysine-coated eightchamber microscope slides. After treatment, cells were fixed with $4 \%$ paraformaldehyde for $20 \mathrm{~min}$ and blocked with $5 \%$ bovine serum albumin- $0.3 \%$ Triton $\mathrm{X}-100$ in phosphate buffered saline (PBS) for $1 \mathrm{~h}$ at room temperature. Cells were incubated with primary antibody at $4{ }^{\circ} \mathrm{C}$ overnight. Antibodies used were as follows: $\alpha$-tubulin, cleaved caspase-3, Drp1, mitofusin-2, followed by incubating with secondary antibody. Samples were mounted with mounting medium with DAPI (Abcam). Images were acquired with a confocal laser scanning microscope (Zeiss LSM880).

\section{Cell-cycle analysis}

To study cell cycle distribution, cells were cultured with UTD1, collected and fixed with $70 \%$ ethanol at $-20^{\circ} \mathrm{C}$ for more than $24 \mathrm{~h} .500 \mu \mathrm{l} \mathrm{PI} / \mathrm{RNase}$ staining buffer was added and incubated for $15 \mathrm{~min}$ at room temperature protected from light. Flow cytometry was performed (BD LSRFortessa) and data were analyzed by FlowJoV10.

\section{Apoptosis analysis}

After incubation with drugs, cells were collected and resuspended in $100 \mu \mathrm{l}$ of $1 \times$ binding buffer containing $5 \mu \mathrm{l}$ fluorescent-labeled Annexin V and $5 \mu \mathrm{l}$ propidium iodide (PI), incubated for $15 \mathrm{~min}$ in dark. Samples were analyzed by flow cytometry and data were analyzed by FlowJoV10.

\section{Western blotting analysis}

Proteins are detected by Western blotting. After incubation, cell lysates were heated in 1x SDS loading buffer for $15 \mathrm{~min}$ at $100^{\circ} \mathrm{C}$. Proteins were separated by SDSPAGE gel, after being transfered to $0.45 \mu \mathrm{m}$ polyvinylidene fluoride membranes, blocked with $5 \%$ BSA for $1 \mathrm{~h}$. Membranes were incubated with antibodies against cyclinB1, cyclinA2, CDC2, P21, PARP, p-JNK, and 
GAPDH at $4{ }^{\circ} \mathrm{C}$ overnight. Secondary antibody was incubated for $1 \mathrm{~h}$. Bands were detected by a chemiluminescence imaging system (Amersham Imager 600) with Super ECL Detection Reagent (Yeasen, Shanghai, China). Results were analyzed by Image J.

\section{Quantitative Real-Time Polymerase Chain Reaction (qRT- PCR)}

Total RNA was extracted from RKO, SW620, CACO2, and HCT15 cells using TRIzol reagent (Invitrogen, USA). The cDNA was synthesized with PrimeScript ${ }^{\mathrm{TM}}$ RT Master Mix (Takara, Japan). qRT-PCR was carried out on LightCycler480 System (Roche, Switzerland) using TB Green ${ }^{\mathrm{TM}}$ Premix Ex Taq ${ }^{\mathrm{TM}}$ (Takara). The primers are as follows: ABCB1:5'-GATTGCTCACCGCCTGTCCAC-3' and 5' ${ }^{\prime}$-CG TGCCATGCTCCTTGACTCTG-3'; GAPDH:5'-ACATCG CTCAGACACCATGG- $3^{\prime}$ and $5^{\prime}$-ACCAGAGTTAAAAG CAGCCCT-3'.

\section{Transmission Electron Microscope (TEM)}

After treatment, RKO cells or tumor tissues were fixed with $2.5 \%$ glutaraldehyde at $4{ }^{\circ} \mathrm{C}$ for $1 \mathrm{~h}, 1 \%$ osmic acid was added at $4{ }^{\circ} \mathrm{C}$ for another $1 \mathrm{~h}$. After alcohol dehydration, samples were infiltrated for $1.5 \mathrm{~h}$ and immersed in pure epon 812 overnight. Then they were polymerized at $65^{\circ} \mathrm{C}$ for 2 days. Samples were observed and imaged using TEM (Talos L120C).

\section{Mitochondrial membrane potential analysis}

Tetramethylrhodamine (TMRM) and Mito Tracker Green (Invitrogen) were used to monitor mitochondrial in RKO cells. After being treated, cells were incubated with TMRM and Mito Tracker Green at $37^{\circ} \mathrm{C}$ for $30 \mathrm{~min}$. Cells were washed with medium and analyzed with a confocal laser scanning microscope.

\section{Measurement of ROS generation}

Reactive Oxygen Species Assay Kit (Beyotime, Shanghai, China) was used to detect intracellular ROS generation. RKO cells were exposed to UTD1 with or without Trolox. Cells were stained with $10 \mu \mathrm{M}$ DCFH-DA at $37^{\circ} \mathrm{C}$ for $20 \mathrm{~min}$. The level of ROS was measured by flow cytometry.

\section{In vivo xenograft mice experiment}

All animal experiments were conducted according to the principles of the Institutional Animal Care and Use Committee at Shanghai Jiaotong University. Six-week BALB/c-nu female mice (Shanghai Slac Laboratory Animal Co., Ltd., Shanghai, China) weighing approximately $20 \mathrm{~g}$ were introduced to establish xenograft tumor model. $4 \times 10^{6}$ RKO cells were subcutaneously injected into right flank of mice in $200 \mu \mathrm{l}$ RPMI-1640 medium. When tumor volume reached about $100 \mathrm{~mm}^{3}$, mice were randomly assigned to different groups $(n=5)$ and treated every two days for 20 days. 4 groups were treated with UTD1 $(2.5 \mathrm{mg} / \mathrm{kg}$ and $5 \mathrm{mg} / \mathrm{kg}$, ip), paclitaxel $5 \mathrm{mg} / \mathrm{kg}$ (ip) or vehicle control. Three groups were treated with UTD1 ( $2.5 \mathrm{mg} / \mathrm{kg}$, ip), 5 -FU ( $25 \mathrm{mg} / \mathrm{kg}$, ip), or vehicle control. Tumor size was measured and mice were weighed every three days. Tumor volume was calculated by the formula: $V=0.5 \times a \times b^{2}$, where $a$ was the length $(\mathrm{mm}), b$ was the width $(\mathrm{mm})$, and $V$ was the volume of tumor. At the end of the experiment, all mice were killed and weights of tumor were recorded. To assess anticancer activity of drugs, percentage of inhibition was calculated as following: Inhibition\% $=(1-$ mean of tumor weight of treated group/mean of tumor weight of control group) $\times 100 \%$.

\section{Immunohistochemistry (IHC) analysis}

Immunohistochemical staining for p-JNK, Ki-67, and Cytochrome $\mathrm{C}$ was performed according to the manufacturer's instruction. Briefly, sections were incubated with blocking solution for $1 \mathrm{~h}$ at room temperature, followed by overnight incubation with primary antibodies at $4{ }^{\circ} \mathrm{C}$. After being incubated with horse anti-Rabbit IG for $2 \mathrm{~h}$ at room temperature and mounted, specimens were observed under microscopy.

\section{Statistical analysis}

All results are given as mean \pm SD. Statistical analysis was performed using GraphPad Prism 8. One-way ANOVA and unpaired Student's $t$ test were used to calculate differences among various experimental groups. $P$ values $<0.05$ were considered statistically significant.

\section{Acknowledgements}

We thank the staff members of the Bioimaging Facility and Electron Microscopy System at Shanghai Institute of Precision Medicine for providing technical support. And we appreciate Prof. Shiyan Yu and Prof. Yanjie Zhang for their guidance on this research. UTD1 was supplied by Biostar Technologies, Ltd. (Beijing, China).

\section{Author details \\ 'State Key Laboratory of Oncogenes and related Genes, Department of Oncology, Renji Hospital, School of Medicine, Shanghai Jiao Tong University, Shanghai 200127, China. ${ }^{2}$ Department of Oncology, the Affiliated Cancer Hospital of Zhengzhou University, Henan Cancer Hospital, NO.127, Dongming Road, Zhengzhou 450008, China. ${ }^{3}$ Shanghai Institute of Precision Medicine, Shanghai 200125, China}

\section{Author contributions}

Shuiping Tu was responsible for conception and design, supervision, writing-review and editing; Fuli Li was responsible for design, data curation, writing-original draft, and investigation; Tinglei Huang was responsible for design, methodology, and investigation; Yao Tang was responsible for analysis of data and investigation; Qingli Li was responsible for resource and validation; Jianzheng Wang was responsible for visualization and investigation; Xiaojiao Cheng, Wenhui Zhang, Baiwen Zhang, and Cong Zhou were responsible for investigation. All authors read and approved the final manuscript.

\section{Funding statement}

The project was supported by NSFC 81773259, NSFC 81472727, NSFC 91029718, Science and Technology Commission of Shanghai Municipality 
(15JC1403100) and National laboratory of Oncogene and Cancer-related Genes foundation (90-15-05).

\section{Conflict of interest}

The authors declare no competing interests.

\section{Ethics statement}

All animal experiments were approved by the Institutional Animal Care and Use Committee at Shanghai Jiaotong University.

\section{Publisher's note}

Springer Nature remains neutral with regard to jurisdictional claims in published maps and institutional affiliations.

Supplementary information The online version contains supplementary material available at https://doi.org/10.1038/s41419-021-03619-6.

Received: 25 October 2020 Revised: 4 March 2021 Accepted: 8 March 2021 Published online: 01 April 2021

\section{References}

1. Brenner, H., Kloor, M. \& Pox, C. P. Colorectal cancer. Lancet 383, 1490-1502 (2014).

2. Martini, G. et al. Resistance to anti-epidermal growth factor receptor in metastatic colorectal cancer: what does still need to be addressed? Cancer Treat. Rev. 86, 102023 (2020).

3. Cremolini, C., Antoniotti, C., Moretto, R., Masi, G. \& Falcone, A. First-line therapy for $\mathrm{mCRC}$ - the influence of primary tumour location on the therapeutic algorithm. Nat. Rev. Clin. Oncol. 14, 113 (2017).

4. Cassidy, S. \& Syed, B. A. Colorectal cancer drugs market. Nat. Rev. Drug Discov. 16, 525-526 (2017).

5. Dekker, E., Tanis, P. J., Vleugels, J. L. A., Kasi, P. M. \& Wallace, M. B. Colorectal cancer. Lancet 394, 1467-1480 (2019).

6. Lee, H.-O. et al. Lineage-dependent gene expression programs influence the immune landscape of colorectal cancer. Nat. Genet. 52, 594-603 (2020).

7. Chen, X. et al. METTL14-mediated N6-methyladenosine modification of SOX4 mRNA inhibits tumor metastasis in colorectal cancer. Mol. Cancer 19, 106 (2020).

8. Shang, J. et al. Small-molecule activating SIRT6 elicits therapeutic effects and synergistically promotes anti-tumor activity of vitamin $D$ in colorectal cancer. Theranostics 10, 5845-5864 (2020).

9. Schiff, P. B. \& Horwitz, S. B. Taxol stabilizes microtubules in mouse fibroblast cells. Proc. Natl Acad. Sci. USA. 77, 1561-1565 (1980)

10. Jordan, M. A. \& Wilson, L. Microtubules as a target for anticancer drugs. Nat. Rev. Cancer 4, 253-265 (2004).

11. Naaz, F., Haider, M. R., Shafi, S. \& Yar, M. S. Anti-tubulin agents of natural origin: targeting taxol, vinca, and colchicine binding domains. Eur. J. Med. Chem. 171, 310-331 (2019).

12. Barreca, M., Stathis, A., Barraja, P. \& Bertoni, F. An overview on anti-tubulin agents for the treatment of lymphoma patients. Pharmacol. Ther. 211, 107552 (2020).

13. Weaver, B. A. How taxol/paclitaxel kills cancer cells. Mol. Biol. Cell $\mathbf{2 5}$ 2677-2681 (2014).

14. Cao, Y.-N. et al. Recent advances in microtubule-stabilizing agents. Eur. J. Med. Chem. 143, 806-828 (2018).

15. Zhao, Y., Mu, X. \& Du, G. Microtubule-stabilizing agents: new drug discovery and cancer therapy. Pharmacol. Ther. 162, 134-143 (2016).

16. Dy, G. Novel taxanes/epothilones. J. Thorac. Oncol. 5, S490-S491 (2010).

17. Toppmeyer, D. L. \& Goodin, S. Ixabepilone, a new treatment option for metastatic breast cancer. Am. J. Clin. Oncol. 33, 516-521 (2010).

18. Zhang, P. et al. Phase I clinical and pharmacokinetic study of UTD1, a genetically engineered epothilone analog in patients with advanced solid tumors. Cancer Chemother. Pharmacol. 68, 971-978 (2011).
19. Zhang, P. et al. Phase II trial of utidelone as monotherapy or in combination with capecitabine in heavily pretreated metastatic breast cancer patients. J. Hematol. Oncol. 9, 68 (2016).

20. Zhang, P. et al. Utidelone plus capecitabine versus capecitabine alone for heavily pretreated metastatic breast cancer refractory to anthracyclines and taxanes: a multicentre, open-label, superiority, phase 3, randomised controlled trial. Lancet Oncol. 18, 371-383 (2017).

21. Hutchinson, L. Breast cancer: utidelone: burden relief in pretreated women. Nat. Rev. Clin. Oncol. 14, 199 (2017).

22. Pazdur, R. et al. Phase II trial of docetaxel (Taxotere) in metastatic colorectal carcinoma. Ann. Oncol. 5, 468-470 (1994).

23. Overman, M. J. et al. Phase II study of nab-paclitaxel in refractory small bowel adenocarcinoma and CpG island methylator phenotype (CIMP)-high colorectal cancer. Ann. Oncol. 29, 139-144 (2018).

24. Bai, Z. et al. 5-(3,4,5-trimethoxybenzoyl)-4-methyl-2-(p-tolyl) imidazol (BZML) targets tubulin and DNA to induce anticancer activity and overcome multidrug resistance in colorectal cancer cells. Chem.-Biol. Interact. 315, 108886 (2020).

25. Chou, T.-C. et al. Therapeutic effect against human xenograft tumors in nude mice by the third generation microtubule stabilizing epothilones. Proc. Natl Acad. Sci. USA 105, 13157-13162 (2008).

26. Nobili, S., Landini, I., Mazzei, T. \& Mini, E. Overcoming tumor multidrug resistance using drugs able to evade P-glycoprotein or to exploit its expression. Med. Res. Rev. 32, 1220-1262 (2012).

27. Rothermel, J., Wartmann, M., Chen, T. \& Hohneker, J. EPO906 (epothilone B): a promising novel microtubule stabilizer. Semin. Oncol. 30, 51-55 (2003).

28. Lee, S. H. et al. Epothilones induce human colon cancer SW620 cell apoptosis via the tubulin polymerization independent activation of the nuclear factor-kappaB/lkappaB kinase signal pathway. Mol. Cancer Ther. 6, 2786-2797 (2007).

29. Yamaguchi, H., Chen, J., Bhalla, K. \& Wang, H.-G. Regulation of Bax activation and apoptotic response to microtubule-damaging agents by p53 transcription-dependent and -independent pathways. J. Biol. Chem. 279 39431-39437 (2004)

30. Montero, A. J. et al. A phase I clinical, pharmacokinetic, and pharmacodynamic study of weekly or every three week ixabepilone and daily sunitinib in patients with advanced solid tumors. Clin. Cancer Res. 22 3209-3217 (2016).

31. Bollag, D. M. et al. Epothilones, a new class of microtubule-stabilizing agents with a taxol-like mechanism of action. Cancer Res. 55, 2325-2333 (1995).

32. Kumar, A. et al. Interaction of epothilone B (patupilone) with microtubules as detected by two-dimensional solid-state NMR spectroscopy. Angew. Chem. 49, 7504-7507 (2010).

33. Gjyrezi, A. et al. Taxane resistance in prostate cancer is mediated by decreased drug-target engagement. J. Clin. Investig. 130, 3287-3298 (2020).

34. Risinger, A. L. et al. The taccalonolides and paclitaxel cause distinct effects on microtubule dynamics and aster formation. Mol. Cancer 13, 41 (2014).

35. Mason, K. A. et al. Effect of docetaxel on the therapeutic ratio of fractionated radiotherapy in vivo. Clin. Cancer Res. 5, 4191-4198 (1999).

36. Vecchione, A. et al. Fez1/Lzts1 absence impairs Cdk1/Cdc25C interaction during mitosis and predisposes mice to cancer development. Cancer Cell 11, 275-289 (2007)

37. Pellicciotta, I., Yang, C.-P. H., Venditti, C. A., Goldberg, G. L. \& Shahabi, S. Response to microtubule-interacting agents in primary epithelial ovarian cancer cells. Cancer Cell Int. 13, 33 (2013).

38. Li, R., Moudgil, T., Ross, H. J. \& Hu, H. M. Apoptosis of non-small-cell lung cancer cell lines after paclitaxel treatment involves the $\mathrm{BH}$-only proapoptotic protein Bim. Cell Death Differ. 12, 292-303 (2005).

39. Kutuk, O. \& Letai, A. Alteration of the mitochondrial apoptotic pathway is key to acquired paclitaxel resistance and can be reversed by ABT-737. Cancer Res. 68, 7985-7994 (2008)

40. Wertz, I. E. et al. Sensitivity to antitubulin chemotherapeutics is regulated by MCL1 and FBW7. Nature 471, 110-114 (2011).

41. Youle, R. J. Morphology of mitochondria during apoptosis: worms-to-beetles in worms. Dev. Cell 8, 298-299 (2005). 